\section{A STATISTICAL STUDY OF 1,000 CASES OF CHRONIC RHEUMATISM}

\section{PART III}

By E. Lewis-Faning, B.Sc., Ph.D.

(Of the Statistical Staff of the Medical Research Council)

E. Fletcher, M.A., M.D., M.R.C.P.

(Physician Queen Mary's Hospital for the East End, and the British Red Cross Clinic for Rheumatism, and (with Physical Medicine) Royal Free Hospital, Heberden Lecturer in Rheumatism.)

During the last twenty years very little literature of a statistical nature has come into existence in this country on the subject of rheumatism amongst adults, although in child life investigations frequent studies have been made of its incidence amongst juveniles. The principal report on adult rheumatism still remains that on the investigation carried out in 1924 by a committee of the medical staff of the Ministry of Health ${ }^{1}$. The committee analysed records of 2,510 cases of rheumatism collected during I922 amongst a population of 90,89I insured persons exposed to risk. Further reference will be made to this later. Kinnear ${ }^{2}$ applied the conclusions of the committee to estimate the cost of industrial rheumatism to the country on the basis of the I927 insurance experience. Glover ${ }^{3}$ in the three Milroy lectures 1930 discussed the incidence of acute rheumatism, of rheumatism in industry, and of chronic arthritis. Mention should also be made of a summary of two thousand cases of rheumatic disease made by Kerr Pringle ${ }^{4}$ in I929 which deals particularly with the relation between type of rheumatism and occupation.

The present study relates to records of $\mathrm{I}, 000$ cases of rheumatism collected during the eight years I933 to I940 inclusive. Of these, I32 were seen and treated at the Royal Free Hospital, 658 at Queen Mary's Hospital for the East End, and 2ro at the British Red Cross Clinic.

Of the information recorded, the following items provided the data utilised in the statistical analysis: Diagnosis (type of rheumatism); name, age, sex and occupation of the patient; family history, past history, duration of the disease when first seen; joint, muscle or nerve affected; whether or not obesity and/or hypertension was present; the blood sedimentation rates; duration of treatment, and whether when last seen any improvement had resulted from the treatment.

The specific problems which have been dealt with are:-
(I) the relation between the frequency of certain types of rheumatism and age, sex, occupation, site affected, the presence or absence of obesity and hypertension, and the blood sedimentation rate.

(2) the relation between diagnosis and response to treatment, duration of disease, and length of treatment.

Owing to wartime restrictions it has not been possible to publish in full the tabulation of the data; in fact, many tables have been entirely omitted, and only the deductions drawn from them stated. Where this has been done is generally indicated in the text, but those interested may obtain full access to the original tabulation on application to the author.

\section{Distribution of cases by diagnosis and sex.}

The classification of the types of rheumatism, the abbreviations used to denote them throughout this section, and the number of cases of each type, distinguishing sex, are the same as appear in Part I, Table I (Vol. xxi, p. 8):

Statistical tests* showed males and females to have a different distribution. Infective or true rheumatoid arthritis comprised 30 per cent of all female cases, but only i5 per cent of the male cases. When osteoarthritis of the spine was combined with osteoarthritis (A-N) so that the group covered osteoarthritis of all parts of the body except hips, then $3 \mathbf{I} \cdot 2$ per cent of all female cases, but only $16 \cdot 0$ per cent of the male cases (a difference of $15.2 \pm 3.0$ per cent) were included. Osteoarthritis of the hips on the other hand was more prevalent amongst the males, as also was fibrositis, gout and sciatica. Apart from their importance, these differences indicated the necessity of treating the sexes separately in most sections of the report.

A cautionary word must be inserted here against accepting any deductions made as having been proved applicable to the general population. On various grounds this would be false generalisation, but principally because we do not know to what extent these cases are selective, or, on the contrary, to what extent they are representative of the general population or any section of it.

In the Ministry of Health's report ${ }^{1}$ it was possible to relate the cases collected to a definite portion of the insured population, and so regard the incidence of rheumatism found as representative of that in the insured population; our cases could not be related to any known population exposed to risk. But if it be accepted that the

* Throughout this report the criteria of significance adopted is that of twice the standard error. A difference to be real, i.e. unlikely to have arisen by chance, must exceed twice its standard error. 
Ministry of Health's data were representative then it is of interest to compare the two series of cases from certain aspects, making allowance for several distinctive features. The Ministry of Health series were drawn from all parts of England and Wales, whereas our data were drawn principally from Greater London. The insured population would not have included housewives who were not otherwise employed; 497 of the 676 females in our data were classed as housewives. In the Ministry of Health's series the ratio of males to females was 2.4 to $I$; in our series, if we exclude the housewives, it was $I \cdot 8$ to $I$.

The age distribution of this series of patients, irrespective of diagnosis, was as follows:- were similar $\left(X^{2}=3.08 ; P=0.69\right.$ (see below)). Since differences between the sexes when diagnosis is considered may be masked in this tabulation, the average age of the patients suffering from each type of rheumatism was calculated. The mean ages for each sex are given in Table I8, together with their standard errors.

When the differences between the sexes were examined, only for two types was a significant difference found, (I) Osteoarthritis group A, already discussed in Table IV (Vol. xxi, p. I2) the females in this group being on the average five years younger than the males, and (2) four male patients with a mean age of 19.5 years, suffering from subacute rheumatism, compared with fourteen female Age Distribution-All Types Combined-Distinguishing Sex

\begin{tabular}{|c|c|c|c|c|c|c|c|c|c|c|}
\hline \multicolumn{4}{|c|}{ Age in years } & o- & $25-$ & $35-$ & $45-$ & $55-$ & $65+$ & Total \\
\hline $\begin{array}{l}\text { Males } \\
\text { Females }\end{array}$ & $\ddot{*}$ & $\begin{array}{l}\cdots \\
\cdots\end{array}$ & $\begin{array}{l}\cdots \\
\cdots\end{array}$ & $\begin{array}{l}16 \\
37\end{array}$ & $\begin{array}{l}35 \\
81\end{array}$ & $\begin{array}{r}53 \\
104\end{array}$ & $\begin{array}{r}78 \\
185\end{array}$ & $\begin{array}{r}97 \\
\mathbf{1} 72\end{array}$ & $\begin{array}{l}45 \\
97\end{array}$ & $\begin{array}{l}324 \\
676\end{array}$ \\
\hline
\end{tabular}

The insured population includes only persons of ages over $\mathrm{r}_{5}$, so that the two series can only be compared above this limit. The percentage age distribution for this section of both series was:-

patients with a mean age of 34.8 years.

It was concluded, therefore, that between male and female patients there was but little material difference in the age distribution of the two series,

Percentage Age Distribution of Cases aged $I_{5}$ and Over, compared with that in the Ministry of Health's Report, I924

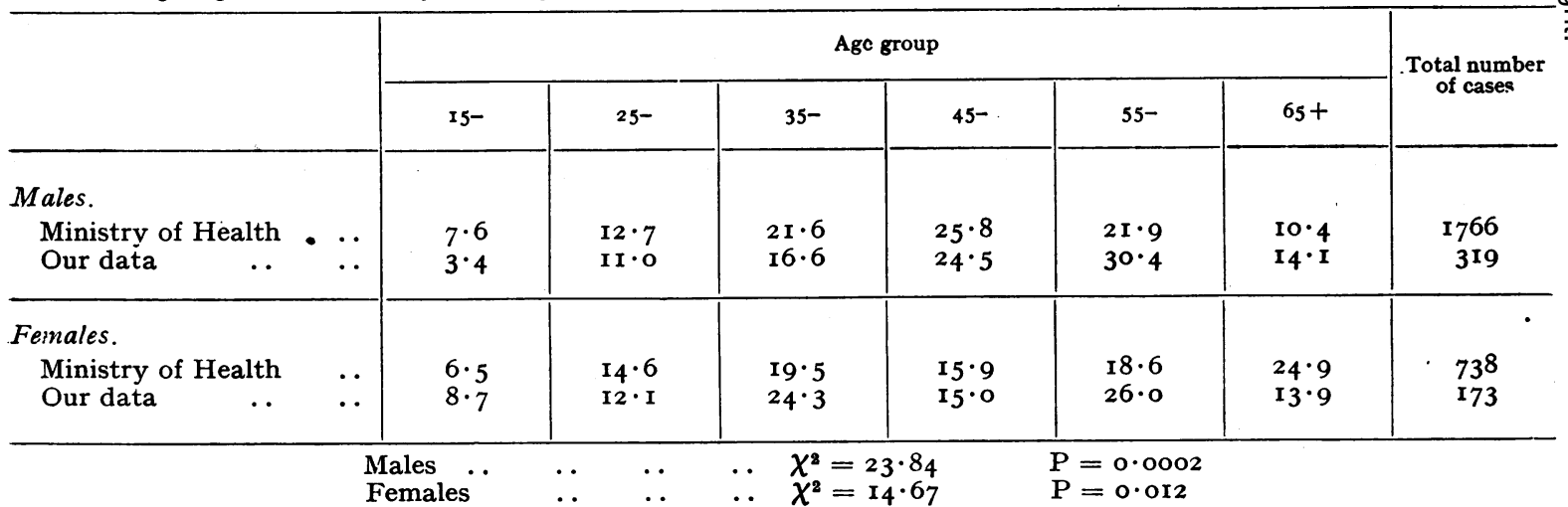

Statistical tests show the distributions to be dissimilar, the proportion of the cases in our series at ages between I5 and 24 being much lower than in the Ministry of Health series; whilst our data are somewhat overweighted by males at ages over 55. The latter feature is probably what one would expect since by geographical situation, the heavy metal and coal-mining industries, which tend to discard the older lives, are excluded from our series.

\section{Analysis of Age.}

Statistical tests applied to the figures showed that the male and female distributions by age either as a whole or for the individual types of rheumatism.

The problem as to whether age is a factor in the type of rheumatism experienced was studied by comparing the mean age for each type with the mean age of all types combined.* Reference has

* The method adopted was justified for males, by the fact that nine out of twenty-two types had a fair proportion of cases, whilst groups with less than ro cases accounted for only 23 per cent of the total number. Hence it cannot be objected that the age of all types combined was determined by any one particular type. For females, since 30 per cent of the cases were of infective arthritis, there is no doubt that here the average of all types was determined by this diagnosis. 
already been made in Part I, Table V (Vol. xxi, p. I2) to this point as regards the osteoarthritis groups.

As would be expected from the fact that there was little difference between the age distributions of male and female patients, there is fair agreement between the sexes in this respect. As can be seen in Table XVIII, if the average age for a particular type of rheumatism is above the grand mean for one sex, so it is for the other sex also in every case. The same is true if it is below the grand mean. Where a significant difference between the type mean and the grand mean occurs for males, it occurs also for females with the one exception of sciatica. That there are more significant differences for females than males is due to the fact that there are double the number of female cases, and the likelihood of chance events is lessened thereby.

Generally, in this series of data, patients suffering from sub-acute rheumatism, rheumatic fever, and malposition of the spine are between fifteen and thirty years younger than the average of all patients, which is approximately fifty years for either sex. The mean age of patients with ankylosing spondylitis is between six and seven years below the grand mean. Patients with infective arthritis, occupational arthritis, (OA.K) fibrositis, osteo-chondritis, sciatica, Bell's palsy, and the unclassified group, are all on the average below the grand mean, but not significantly so for both sexes taking into account the numbers in the group and the variability around the mean. On the other hand, those with osteoarthritis of the spine, gout, brachial neuritis, and osteoarthritis with obesity, but normal blood pressure, are somewhat above the average, but not significantly so in both sexes. Types which indicate a significantly older class of sufferer are Periarthritis of the shoulder, osteoarthritis, groups $\mathrm{A}, \mathrm{D}, \mathrm{N}$ and $\mathrm{H}$, and osteoarthritis of the hips, the last-named having an average age of sixty-two years.

\section{Broad classification of types.}

So far, each type of rheumatism has been kept separate, but in view of the small number of cases occurring in certain groups and of the impossibility of drawing valid conclusions from so small numbers, subsequent analysis was based on broader groupings, viz.:-

$$
\begin{array}{crl}
\text { Male } & \text { Female } \\
4^{8} & 206 & \text { I.A. } \\
22 & 31 & \text { S.A. } \\
34 & 89 & \text { OA. (A) and O.A. Spine. } \\
32 & \text { I } 53 & \text { OA. (B.D.N.H.K.). } \\
29 & - & \text { OA. Hips. } \\
19 & - & \text { Gout. }
\end{array}
$$

Male Female-continued.

$48 \quad 66$ Fibrositis.

5I 4I Interstitial Neuritis: (Sciatica, Brachial N., Bell's Palsy, and others).

4I 90 Miscellaneous group comprising Osteochondritis, sub-acute R; Rheumatic Fever, Malposition of the spine, Periarthritis of shoulders, and the unclassified group.

Where necessary the $\mathrm{I}_{5}$ female cases of $\mathrm{OA}$. hips were included with OA. (B-K), and the 2 I female cases of gout transferred to the miscellaneous group.

\section{Analysis of occupations.}

The problem of determining whether any relation exists between type of rheumatism and the occupation of the patient is an important one. It was necessary to devise some relevant classification by which the data could be grouped since the occupations followed by the male patients were almost as numerous as the patients themselves, and although amongst females, housewives formed 73.5 per cent of the total, the remainder covered a wide and varied range. It was evident that a different type of classification was needed for the two sexes, and the following broad groupings were made.

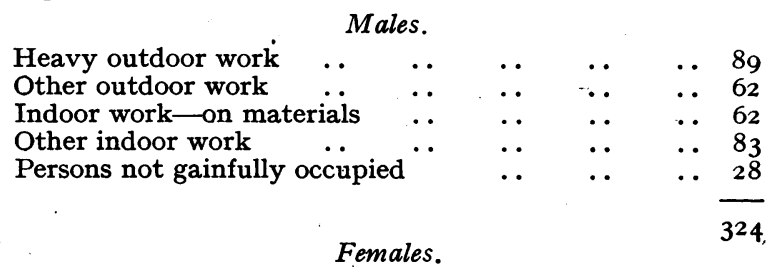

House duties, retired and unemployed $\quad$.. $\quad \ldots 553$ Office workers and shop assistants $\quad \ldots \quad \ldots .62655$ Factory workers, etc., and cleaners $\quad \ldots \quad \ldots \quad \ldots 5^{8}$

Space does not permit listing in detail the occupations included in each of the above broad groups, but it can be stated that of the 324 males, 55 were labourers (undefined), 30 were clerks and office workers, I8 were railway workers, II were stevedores and dockers, and the remainder were spread over 70 different occupations, with never more than ro alike.

Of the 676 females, apart from 497 housewives, there were 24 domestics, 21 clerks, I5 typists, the rest being spread over 55 occupations, in very small groups.

The great majority of patients were drawn, therefore, from the three social types defined in the Registrar-General's reports as skilled, unskilled and intermediate-social classes III; IV and V. But when the proportions in the largest groups numerically in our series were compared with the proportions in Greater London we obtained:- 


\section{Males}

All Occupations in Social classes

III, IV and V

Labourers (undefined) $\cdots$

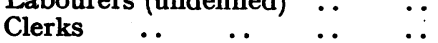

Railway workers ${ }^{\cdots} \quad \ldots . \quad$..

Stevedores and dockers ...

For females, no such comparison is possible, since only married women are graded in the official reports according to social class, that in which their husband's occupation falls. this proportion is higher or lower in Greater London we cannot say, but assuming it to be the same as for the whole country we find that housewives represent 88.8 per cent of all married women. In our rheumatism series married women number $56 \mathrm{I}$ and housewives represent $88.5 \mathrm{per}$ cent of this number, a remarkable agreement.

It is a justifiable conclusion, therefore, from this series of patients, that the incidence of rheumatism amongst housewives was on the same level as that experienced by "occupied" married women."

In Tables I9A and I9B the percentage distribu-

TABLE 18

Average Age of Patients by Type of Rheumatism-Distinguishing Sex

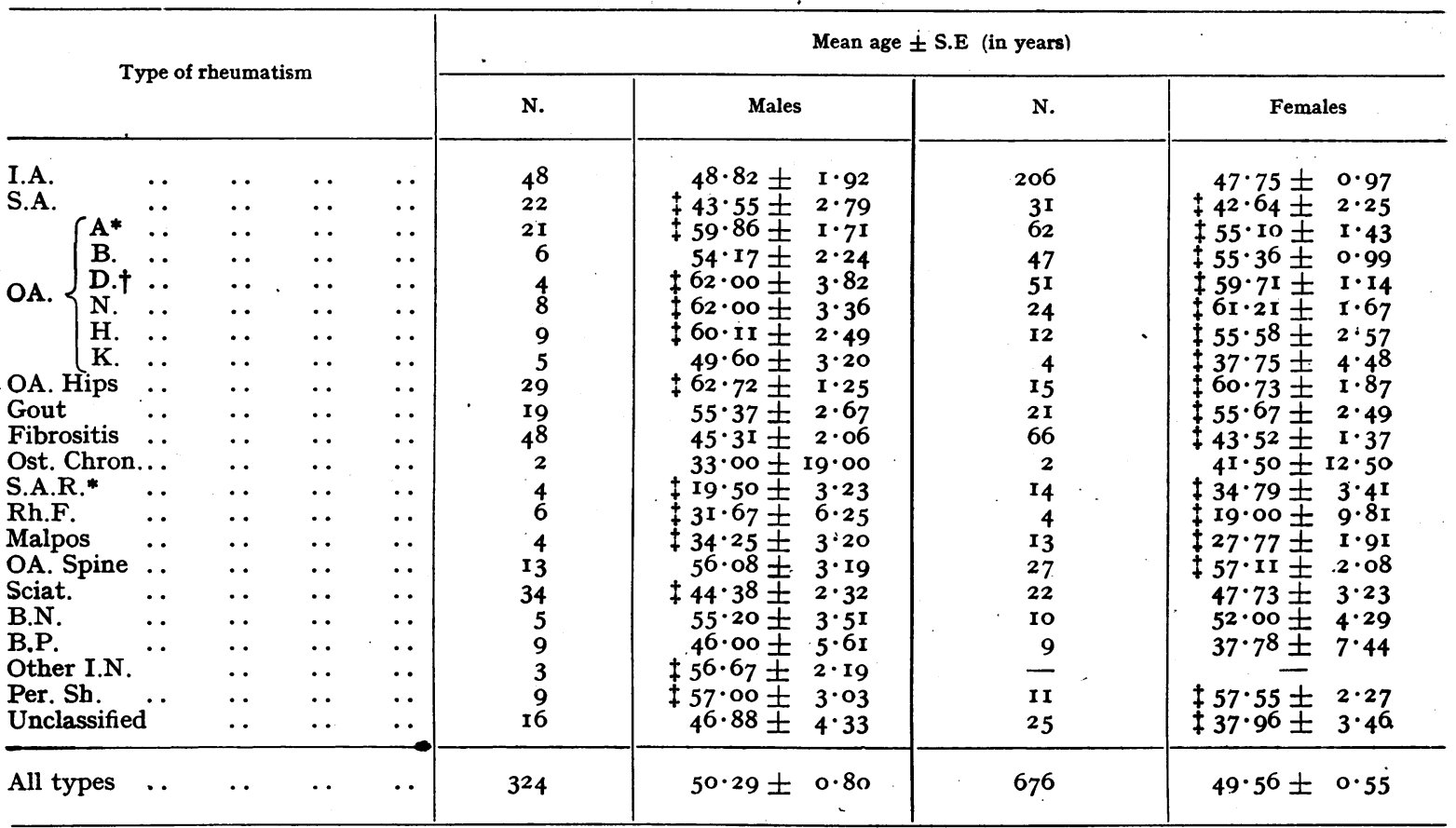

* Indicates significant difference between the mean ages of the sexes as regards the same type of rheumatism.

t The subdivisions of osteoarthritis used in this paper are fully set out in Part I, Vol. xxi, p. 6, together with the abbreviations used throughout both parts.

‡Indicates significant difference between the mean age of the type and the mean age of all types combined.

It is possible, however, from the I93I Census volumes to arrive at an approximate estimate of the proportion of married women in England and Wales whose husbands are in occupations included in classes III-V, who are "housewives."* Whether

* This estimate was obtained as follows: Total married women in III-V (Table $4^{\mathrm{B}}$ Occupational mortality, England and Wales, I931) $=6,877,340$. Assume that gainfully occupied wives are, on the whole, engaged in occupations of the same social class as their husband's occupations. Then it may be calculated that of the total 896,702 "occupied" married women, 773,236 were in social classes III-V.

Hence $6,877,340-773,236=6$, I04, 104 wives not gainfully occupied in classes III-V; and ratio of this to total married women in the same classes $=88 \cdot 8$ per cent. tions of the types of rheumatism are shown for each occupational group. For example, of the 89 cases of rheumatism which occurred amongst heavy outdoor workers, 14 or 15.7 per cent were fibrositis, 9 per cent infective arthritis, etc. Chisquare tests, the results of which are shown at the foot of the tables, showed that the distributions were significantly different for the occupation groups, and the Coefficients of Contingency (C) obtained were 0.398 for males and 0.209 for females, from which it was evident that there was some relation between occupation and type of rheumatism.

In order to examine in detail the nature of this 
relationship we calculated the difference between the proportion of each type of rheumatism occurring in any occupation group and the proportion occurring in all other groups. For example, of the 89 cases amongst heavy outdoor workers, I7 or I9. I per cent were of osteoarthritis (group $\mathrm{A}+$ Spine). Of the 235 cases occurring amongst males of other occupations $I 7$, or $7 \cdot 2$ per cent, were of this type. The excess $\mathrm{II} \cdot 9 \pm 3.8$ per cent is significant. Space precludes the tabulation of all differences, but the following were unlikely to have arisen from the play of chance.

Thus heavy outdoor workers show excess of OA., groups A + Spine; while other outdoor workers show excess of interstial neuritis. Indoor workers on materials suffer particularly from both infective arthritis, and osteo-arthritis groups $\mathrm{B}-\mathrm{K}$; but other types of indoor workers are much troubled with ankylosing spondylitis and miscellaneous types of rheumatism. Females working on house duties have an excess of osteoarthritis, all groups except $\mathrm{A}+$ Spine. Office and shop workers suffer particularly with ankylosing spondylitis, but factory workers and cleaners are particularly affected by fibrositis, gout and miscellaneous types.

Before it can be definitely concluded that these differences are associated with occupation, the age differences between the occupational groups must be taken into account, for it has been demonstrated (Table I8) that age and type of rheumatism are related.

Examining this point, no significant difference could be proved to exist between the male groups as regards age, but females engaged in house duties were on the average eleven years older than those working in offices, shops and factories. Whilst it is safe, therefore, to conclude that the differences between the occupation groups as regards excess of a particular type of rheumatism are due to the occupational factor in males, it is not clear as regards females whether the age or the occupational factor is the more important. For Table I8 has shown that patients suffering from ankylosing spondylitis and from certain types which are included in the miscellaneous group are on the average younger than those suffering from other types. It may be, therefore, that the excess of ankylosing spondylitis found in shop workers and of the miscellaneous group amongst factory workers is due to the younger ages of these groups and not to the occupation. But since the occupational factor is clearly of primary importance amongst males, one is inclined to accept this explanation as regards females also.

\section{Obesity and Hypertension}

All cases in which obesity or hypertension was present were noted. Since it appeared desirable in this connection to keep separate osteoarthritis associated or not associated with obesity and high blood pressure, arthritis associated with trauma (OA.H) and occupational arthritis (OA.K) were transferred to the miscellaneous group.

In each type group the percentage of females with obesity was much higher than for males. This was also true as regards hypertension except for osteoarthritis of the hips, where, however, the excess for males was not significant. But it would

TABLE I9A

Percentage Distribution of each Occupation Group by Type of Rheumatism

Males.

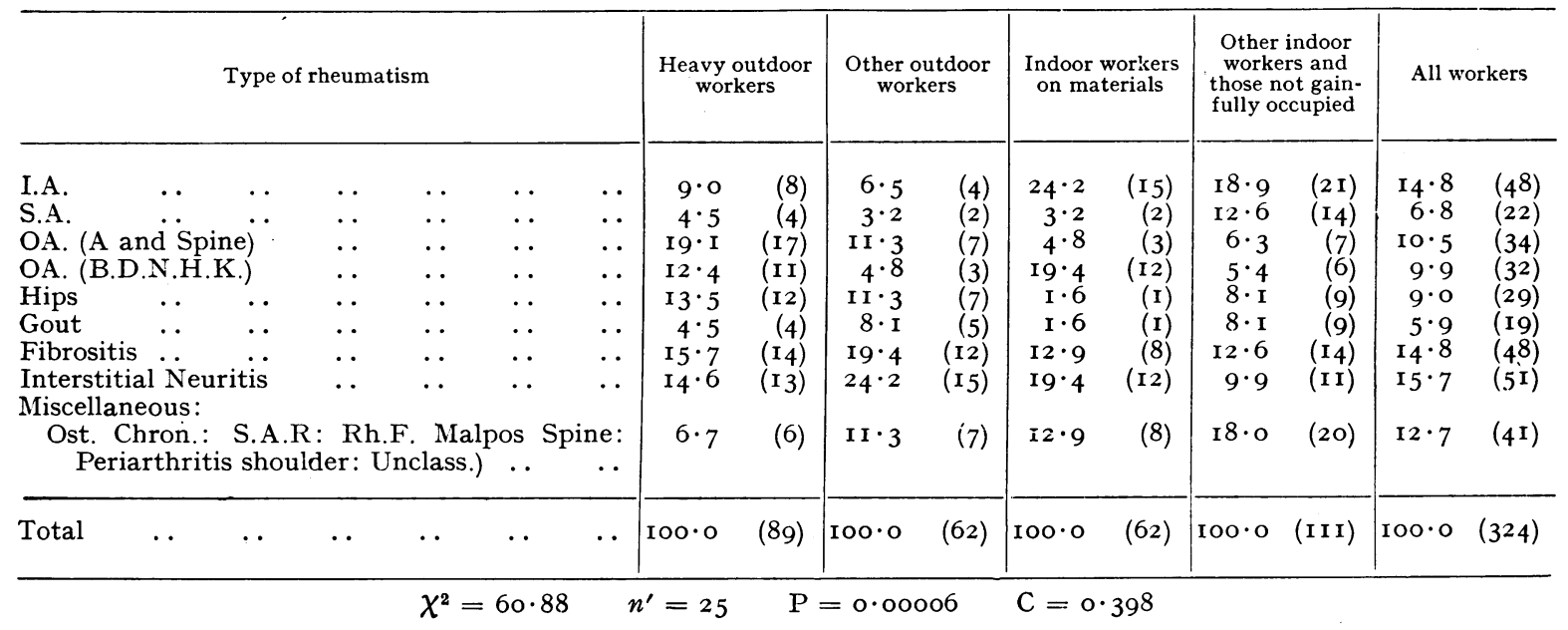


TABLE I9B

Percentage Distribution of each Occupation Group by Type of Rheumatism.

Females.

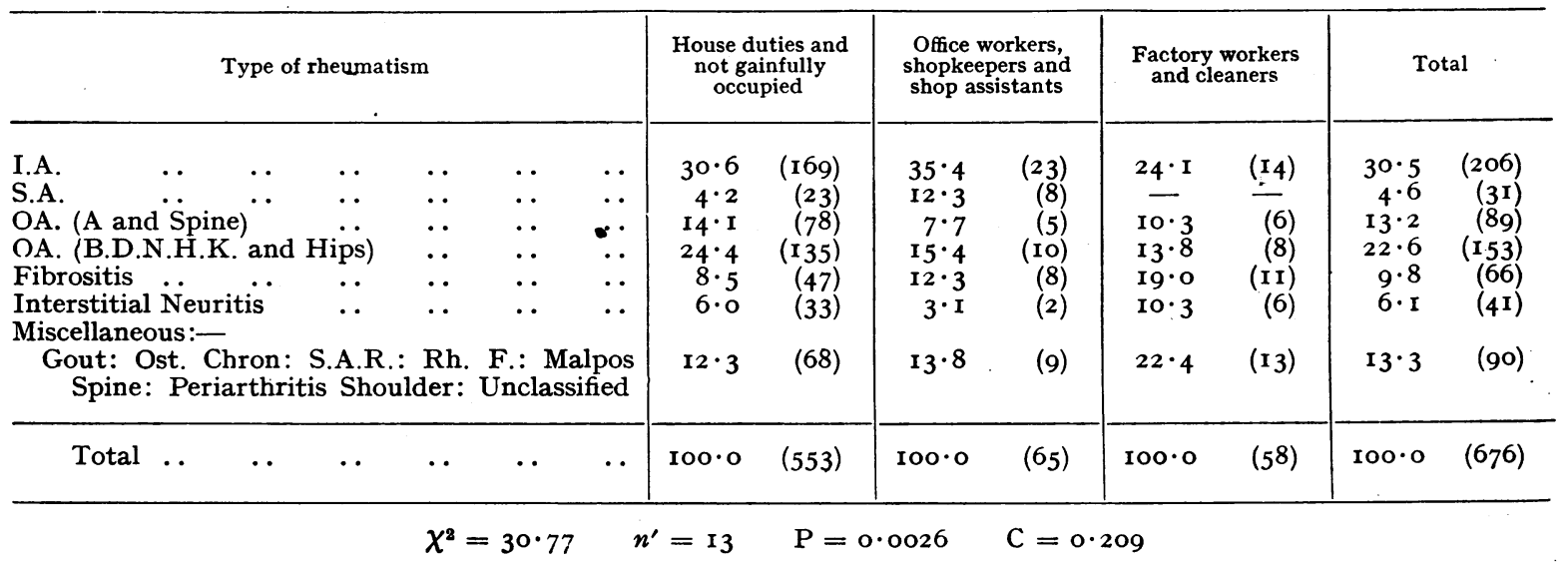

The figures in parentheses are the number of cases from which the percentages are derived.

be unsafe to assume on these grounds any relation between rheumatism, sex and obesity or hypertension, for the results probably merely reflect a similar state of affairs in the general population. We know of no statistics on obesity or hypertension amongst the general adult population of
I7.3 females). For females, the obesity rate for osteoarthritis of the spine and hip $(25.9$ and $40 \cdot 0$ per cent) are not significantly lower than the rate for osteoarthritis of all other sites, and we may therefore calculate the combined rate for all sites of osteoarthritis (OA. A $-\mathrm{N}+\mathrm{OA}$.

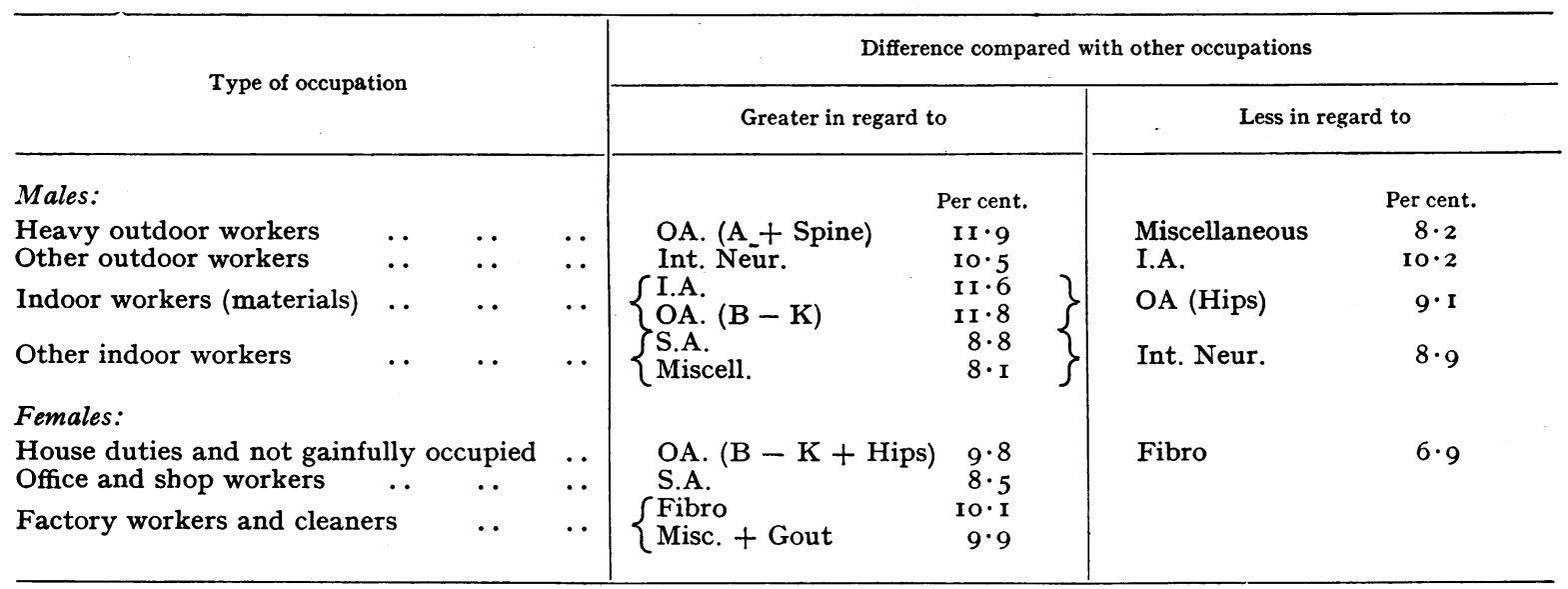

this country which would enable this point to be tested.

In this series of patients obesity was more highly associated with osteo-arthritis (excluding spine and hips) than with other types of rheumatism. It was present in 20 per cent of the male and 5I per cent of the female patients thus diagnosed, and these proportions are significantly higher than those for all other patients $(3.2$ males, spine + OA. hips) $=47 \cdot 3$ per cent, which is much in excess of that of all other types of rheumatism, I6.0 per cent. (See also Table VI), Vol. xxi, p. I2.)

Very similar deductions may be made as regards hypertension. It was found in 36 per cent of male and 43 per cent of female patients where the diagnosis was osteoarthritis (excluding spine and hips), these rates being significantly above those 
for all other types combined $(\dot{\mathrm{I}} 2 \cdot 3$ per cent males, $22 \cdot 2$ per cent females). The hypertension rates for $\mathrm{OA}$. spine were higher and those for OA. hips lower, but not more so than might arise as the result of chance fluctuation. Hence by combining osteoarthritis of all sites we found that in 38.3 per cent of males and $44^{\circ} 2$ per cent of females with this type of rheumatism, hypertension was present; these rates being significantly above those for sufferers of all other types $(7 \cdot 4$ per cent males, I9. 6 per cent females). (See also Pt. I.)

\section{Sites of Rheumatism.}

The sites of the body attacked by rheumatism in these 1,000 patients were examined under three headings, joints, muscles and nerves in order.

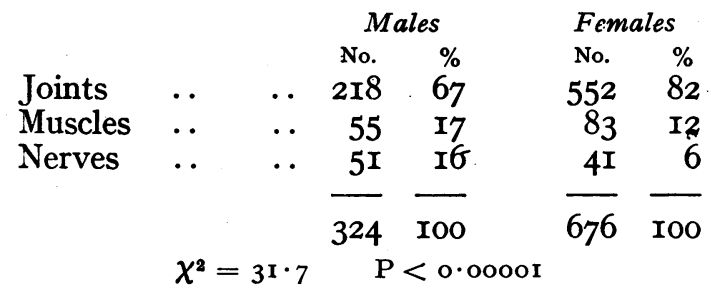

A higher proportion of female than of male patients were attacked in the joints $(82$ and 67 per cent), but for muscles and nerves the proportion was higher amongst males.

(a) Joints.-The joints affected were placed in three categories: Joints of the Spine, Small joints or extremities - the hand being the principal part attacked-and large joints such as elbows, shoulders, hips and knees-the last-named having the greatest frequency.

In Tables $20 \mathrm{~A}$ and $20 \mathrm{~B}$ for males and females respectively; the cases in the three categories are tabulated according to the type of rheumatism diagnosed. In these Tables the upper row of percentages against each category shows the number of cases in each cell expressed as a percentage of the vertical right-hand totals, the lower row shows them as percentages of the horizontal totals. Thus the $2 \mathrm{I}$ cases of S.A. in the first line of Table 20A comprise 50.0 per cent of all cases amongst males in which spinal joints were attacked, or, from another point of view, we may say that of the 22 cases of S.A. amongst males in 21 (or 96 per cent) the sites were the spinal joints.

The deductions drawn from these tables were precisely the same for the two sexes. So that the non-statistical reader should not be troubled with technical details, it need only be said that all differences arising from the specific points were tested for statistical significance and were outside the range of chance events. For the statistical critic a footnote explains what has been done.*

In this series, if the joints of the spine were attacked the diagnosis was generally ankylosis spondylitis or osteoarthritis, and this of course is pictured in the tables. For males, 50 per cent of cases where the spine was attacked were S.A. and 33 per cent $\mathrm{OA}$. (A + Spine). Comparative figures for females were S.A. 34 per cent and OA. (A + Spine) 37 per cent.

Infective arthritis was the principal diagnosis when small joints were in question, for amongst males 50 per cent and amongst females 70 per cent of small joint cases were infective arthritis. Osteoarthritis was rarely found in the small joints.

Of types affecting the large joints OA. (groups $\mathrm{B}-\mathrm{K}$ ) and OA. hips were the most frequent. The diagnosis in the case of 49 per cent of the males and 46 per cent of the females attacked in the large joints was either OA (B-K) or OA. hips.

Regarding this from the diagnostic rather than from the site affected viewpoint, the site of the majority of cases of ankylosis spondylitis was joints of the spine. Most cases of infective arthritis were found in the small joints, and most cases of osteoarthritis (classes $\mathrm{B}-\mathrm{K}$ and hips) in the large joints.

It may be of interest to note that of the 48 male patients with osteo-arthritis (A-K), where the large joints were attacked, the knees were affected in 25 (52 per cent). Comparative figures for females were 162 cases (excluding O.A. hips), the knees being the joint affected in 140 cases (86 per cent).

(b) Muscles affected.-In I7 per cent of the male and 12 per cent of the female patients the site of rheumatism was the muscles. These were classified into four groups roughly corresponding to $(a)$ head, neck, shoulders and trunk; (b) spine, (c) thigh, (d) arms and hands, legs and feet.

The types of rheumatism observed to affect the muscles were fibrositis, sub-acute rheumatism, rheumatic fever (one case only), and the unclassified group. Of these, fibrositis was the only one

* Chi-square tests showed the distributions of the "joint" categories to be entirely different. The principal contributors to the value of $\chi^{2}$ are those discussed in the text, and the proportion contributed by each to the category named was compared with the proportion contributed by all other types combined. For example, amongst the 83 females attacked in spinal joints $37 \cdot 3$ per cent are diagnosed as OA. (A and Spine). Of the 469 attacked in "small" and "large" joints only 12.4 per cent are diagnosed as OA. (A + Spine). The difference $24^{\circ} \cdot \pm 4^{\cdot 4}$ is significant. From another aspect we may argue that of the 89 cases of OA. (A and Spine) amongst females 34.8 per cent were attacked in spinal joints. Of the 463 other cases only I I. 2 per cent affected joints of the spine. The difference $23.6 \pm 4.0$ is again significant. 
TABLE 2OA

Distribution by Joints affected and Type of Rheumatism-Males

\begin{tabular}{|c|c|c|c|c|c|c|c|c|}
\hline \multirow[b]{2}{*}{. } & . & \multirow[b]{2}{*}{ S.A. } & \multicolumn{2}{|c|}{ OA. } & \multirow[b]{2}{*}{ Hips } & \multirow[b]{2}{*}{ Gout } & Miscellaneous & \multirow[b]{2}{*}{ Total } \\
\hline & I.A. & & A and Spine & B.D.N.H.K. & & & $\begin{array}{l}\text { Ost. Chron. } \\
\text { S.A.R., } \\
\text { Rh. F., } \\
\text { Malpos Spine, } \\
\text { Peri. Sh., } \\
\text { Unclass. }\end{array}$ & \\
\hline $\begin{array}{l}\text { Joints of the Spine, etc.: } \\
\text { Cervical Spine } \\
\text { Dorsal Spine } \\
\text { Lumbar Spine } \\
\text { Spine (undefined) } \\
\text { Sacro iliac joints }\end{array}$ & - & $\begin{array}{ll}50 \cdot 0 & \\
95 \cdot 5 & (2 \mathrm{I})\end{array}$ & $\begin{array}{ll}33 \cdot 3 & (14) \\
4 I \cdot 2 & \end{array}$ & $\begin{array}{l}2 \cdot 4 \\
3 \cdot I\end{array}$ & & & $\begin{array}{l}\mathbf{I}_{4} \cdot 3 \\
\mathrm{I}_{7} \cdot 6\end{array}$ & $100 \cdot 0$ \\
\hline $\begin{array}{l}\text { Small joints: } \\
\text { Fingers, hand, wrist, } \\
\text { ankles, feet, toes and } \\
\text { skin of legs }\end{array}$ & $\mid \begin{array}{cc}50 \cdot 0 & \\
56 \cdot 2 & (27)\end{array}$ & & $\begin{array}{ll}5 \cdot 6 & \\
8 \cdot 8 & (3)\end{array}$ & & & $\begin{array}{ll}27 \cdot 8 \\
78 \cdot 9\end{array}$ (I5) & $\begin{array}{l}\mathbf{I} 6 \cdot 7 \\
26 \cdot 5\end{array}$ & $\mid \begin{array}{ll}\text { Ioo. I } \\
24 \cdot 8\end{array}$ \\
\hline $\begin{array}{l}\text { Large joints: } \\
\text { Elbows, Shoulders, } \\
\text { Clavicular, Costo- } \\
\text { Sternal, Hips, Knees }\end{array}$ & $\begin{array}{l}17 \cdot 2 \\
43 \cdot 7\end{array} \quad(2 \mathrm{I})$ & $\begin{array}{l}0 \cdot 8 \\
4 \cdot 5\end{array}$ & $\begin{array}{ll}13 \cdot 9 \\
50 \cdot 0\end{array} \quad$ (I7) & $\begin{array}{cc}25 \cdot 4 \\
96 \cdot 9\end{array}$ & $\mid \begin{array}{cc}23 \cdot 8 & \\
100 \cdot 0 & (29)\end{array}$ & $\begin{array}{c}3 \cdot 3 \\
2 \mathrm{I} \cdot \mathrm{I}\end{array}$ & $\begin{array}{l}\text { I5.6 } \\
55 \cdot 9\end{array}$ & ${ }^{100 \cdot 0}(122)$ \\
\hline Total & $100 \cdot 0 \quad\left(4^{8}\right)$ & I00.0 (22) & I00.0 (34) & $100 \cdot 0 \quad(32)$ & I00.0 (29) & I00.0 (I9) & $100 \cdot 0 \quad(34)$ & IOO. I (2I8) \\
\hline
\end{tabular}

TABLE 2OB

Type of Rheumatism and Joint affected-Females

\begin{tabular}{|c|c|c|c|c|c|c|}
\hline & & & & & Miscellaneous & \\
\hline & I.A. & S.A. & $A+$ Spine & $\begin{array}{l}\text { B.D.N.H.K., } \\
\text { Hips }\end{array}$ & $\begin{array}{l}\text { Gout, } \\
\text { Ost. Chron., } \\
\text { S.A.R., Rh. F., } \\
\text { Malpos Spine, } \\
\text { Peri. Sh., } \\
\text { Unclassified }\end{array}$ & Total \\
\hline $\begin{array}{l}\text { Joints of the Spine, etc.: } \\
\text { Neck and Cervical Spine } \\
\text { Dorsal Spine } \\
\text { Lumbar Spine } \\
\text { Spine (undefined) } \\
\text { Sacro iliac } \\
\text { Vertical column }\end{array}$ & $\begin{array}{l}4 \cdot 8 \\
I \cdot 9\end{array}$ & $\begin{array}{l}33 \cdot 7 \\
90 \cdot 3\end{array}$ & $\begin{array}{l}37 \cdot 3 \\
34 \cdot 8\end{array} \quad$ (3I) & $\begin{array}{l}7 \cdot 2 \\
3 \cdot 9\end{array}$ & $\begin{array}{c}16 \cdot 9 \\
19 \cdot 2 \quad(\mathrm{I} 4) \\
\text {, }\end{array}$ & $\begin{array}{l}99 \cdot 9 \\
\mathrm{I}_{5} \cdot 0\end{array}$ \\
\hline $\begin{array}{l}\text { Small joints: } \\
\text { Finger, hand, wrist, ankles, } \\
\text { feet, toes, and skin of } \\
\text { legs }\end{array}$ & $\begin{array}{l}70 \cdot 4 \\
64 \cdot 6\end{array} \quad$ (I33) & $\begin{array}{ll}I \cdot 0 \\
6 \cdot 5\end{array}$ & $\begin{array}{l}4 \cdot 8 \\
\text { IO }\end{array}$ & $\begin{array}{l}\text { Io.o } \\
\mathrm{I} 2 \cdot 4\end{array}$ & $\begin{array}{l}\text { I3.8 } \\
35 \cdot 6\end{array}$ & $\begin{array}{l}\text { I0o.0 } \\
34 \cdot 2^{(189)}\end{array}$ \\
\hline $\begin{array}{l}\text { Large joints: } \\
\text { Jaw, Elbows, Shoulders, } \\
\text { Clavicular, Costo-Sternal, } \\
\text { Hips, Knees }\end{array}$ & $\begin{array}{ll}24 \cdot 6 & (69) \\
33 \cdot 5 & \end{array}$ & $\begin{array}{l}0 \cdot 4 \\
3 \cdot 2\end{array}$ & $\begin{array}{l}17 \cdot 5 \\
55 \cdot I\end{array}$ & $\begin{array}{l}45 \cdot 7 \\
83 \cdot 7\end{array}$ & $\begin{array}{l}\text { I I } 8 \\
45 \cdot 2\end{array}$ & $\begin{array}{l}100 \cdot 0 \\
50 \cdot 7\end{array}$ \\
\hline Total & $100 \cdot 0(206)$ & $100 \cdot 0 \quad(3 I)$ & Iоo.0 (89) & roo.o (I53) & $100 \cdot 0 \quad(73)$ & $99 \cdot 9 \quad\left(55^{2}\right)$ \\
\hline
\end{tabular}

In each cell are shown the number of cases (in parenthesis), the upper figures are the percentage of the final total column, and the lower figures the percentages of the totals at the foot of each column. 
of importance, comprising 87 per cent of all male, and 80 per cent of all female cases in which muscles were attacked, the difference being of no importance.

Passing to the problem as to whether any particular group of muscles were more or less attacked by any specific type, the percentage of cases due to fibrositis in each muscle group was compared with the percentage due to fibrositis in all other muscle groups. The only statistically significant fact of note was that muscles of the hands, arms, legs and feet were less affected by fibrositis than other groups of muscles.

(c) Nerve affected.-In $5 \mathrm{I}$ or $\mathrm{I} 5.7$ per cent of the male patients and $4 \mathrm{I}$ or $6 \cdot \mathrm{I}$ per cent of the female patients the nerves were affected, such cases being defined as coming under the general heading

TABLE $2 \mathrm{I}$

Type of Rheumatism and Muscles affected

Total cases and percentage due to Fibrositis

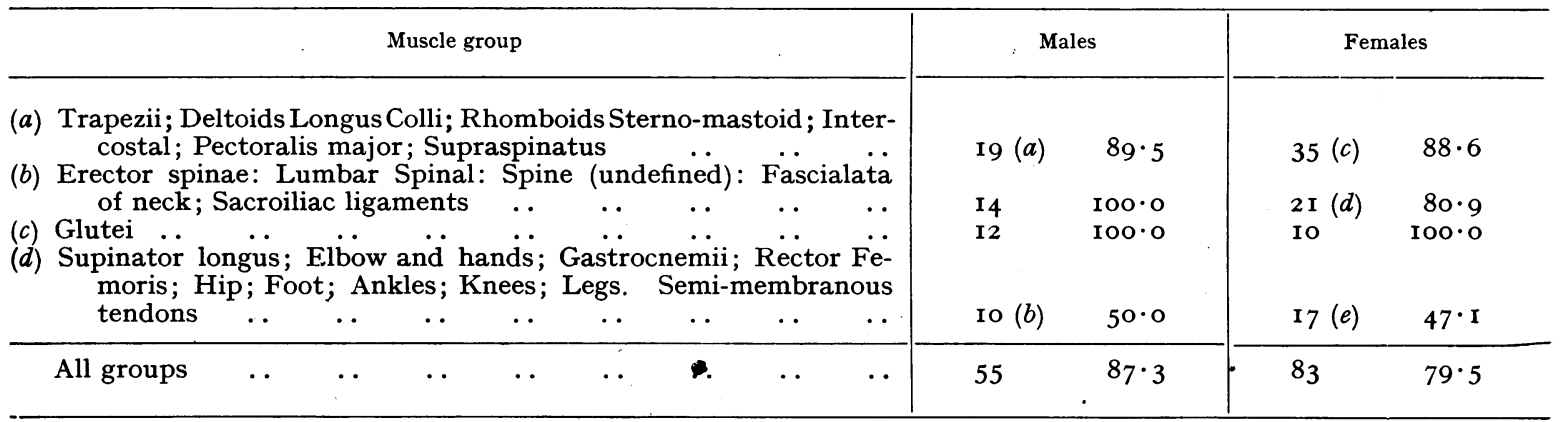

(a) S.A.R. I Unclass. I.

(b) S.A.R. 3 Unclass. 2. (c) S.A.R. 2 Unclass. 2.

(d) S.A.R. 4 .

(e) S.A.R. 7 Unclass. I; R.F. I.

TABLE 22

Frequency Distribution of the Blood Sedimentation Rate when Treatment commencedfor Specified Types of Rheumatism

\begin{tabular}{|c|c|c|c|c|c|c|c|c|c|}
\hline \multicolumn{2}{|c|}{ B.S.R. in mm.s per hour } & $\begin{array}{l}\text { I.A. } \\
23 ?\end{array}$ & S.A. & Gout & $\begin{array}{l}\text { Fibrositis } \\
\left.\begin{array}{c}49 \\
32\end{array}\right\} \text { IOI }\end{array}$ & OA.(A+Spine) & $\frac{\text { OA. }(B-K)}{43}$ & $\frac{\text { OA.(Hips) }}{12)^{\circ}}$ & Total \\
\hline $\begin{array}{l}\text { Normal } \\
\text { Doubtful } \\
\text { Abnormal }\end{array}$ & $\begin{array}{l}0- \\
5- \\
10- \\
15- \\
20- \\
25- \\
30- \\
35- \\
40- \\
45^{-} \\
50- \\
55^{-} \\
60- \\
65^{-} \\
70- \\
75^{-} \\
80^{-} \\
85^{-} \\
90- \\
95^{-} \\
100- \\
105-\end{array}$ & $\left.\begin{array}{r}23 \\
30 \\
30 \\
31 \\
32 \\
9 \\
14 \\
16 \\
8 \\
12 \\
5 \\
3 \\
4 \\
4 \\
2 \\
2 \\
I \\
I \\
I \\
\\
I\end{array}\right\}$ I 45 & $\left.\begin{array}{r}\text { I0 } \\
4 \\
7 \\
6 \\
9 \\
3 \\
3 \\
2 \\
2 \\
2 \\
1 \\
1\end{array}\right\} 21$ & $\left.\begin{array}{r}\text { II } \\
10 \\
4\end{array}\right\} 25$ & $\left.\begin{array}{r}49 \\
32 \\
20 \\
5 \\
2 \\
2 \\
-1\end{array}\right\} 10$ & $\left.\begin{array}{r}\begin{array}{r}38 \\
42 \\
22\end{array} \\
7 \\
2 \\
- \\
- \\
- \\
1\end{array}\right\} \begin{array}{l}10 \\
10\end{array}$ & $\left.\begin{array}{r}43 \\
55 \\
43 \\
10 \\
6 \\
3 \\
1 \\
-1\end{array}\right\} 21$ & $\left.\begin{array}{l}12 \\
17 \\
10 \\
\frac{2}{-}\end{array}\right\} 39$ & $\left.\begin{array}{r}\text { I } 86 \\
190 \\
136 \\
63 \\
54 \\
20 \\
21 \\
20 \\
11 \\
15 \\
6 \\
3 \\
5 \\
4 \\
3 \\
2 \\
1 \\
1 \\
1 \\
- \\
-2\end{array}\right\} 232$ \\
\hline \multirow{2}{*}{\multicolumn{2}{|c|}{$\begin{array}{l}\text { Percentage where } \\
\text { B.S.R. is I } 5 \text { and over }\end{array}$}} & $\begin{array}{l}228 \\
64 \%\end{array}$ & $\begin{array}{l}50 \\
58 \% \\
\end{array}$ & $\begin{array}{l}39 \\
36 \% \\
\end{array}$ & $\begin{array}{l}\text { III } \\
\qquad \underbrace{9 \%}\end{array}$ & $\begin{array}{r}112 \\
9 \% \\
\end{array}$ & $\begin{array}{r}162 \\
13 \% \\
\end{array}$ & $\begin{array}{r}42 \\
7 \% \\
\end{array}$ & \multirow[t]{2}{*}{$\begin{array}{l}744 \\
31 \%\end{array}$} \\
\hline & & & $59 \cdot 3 \%$ & & & & & & \\
\hline
\end{tabular}


-interstitial neuritis, and comprising Sciatica, Brachial neuritis, Bell's palsy, and other interstitial neuritis.

Type of Rheumatism and Nerve Affected.

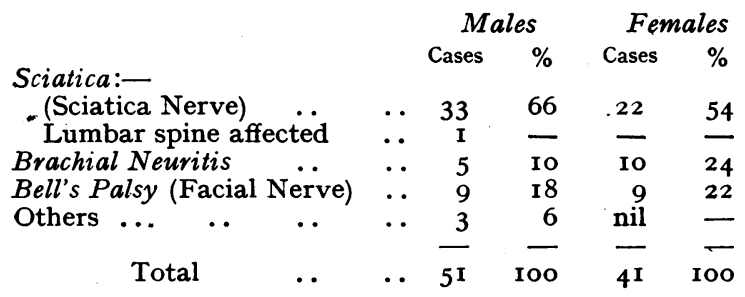

The distribution of the cases according to these four types are similar for the two sexes. In these excluded was relatively small for any type as will be evident from the slight difference between the totals of this and other tables. (See also Pt. I.)

No statistical tests are needed to see that whereas B.S. rates extending up to $107.5 \mathrm{~mm} . \mathrm{s}$ per hour were a feature of I.A. and gout, and up to 62.5 for S.A.; rates higher than $47 \cdot 5$ were not once observed among the osteoarthritic and fibrositic patients. One may even say that whilst B.S. rates higher than 22.5 were of common occurrence in I.A.; S.A. and gout they were unusual in osteoarthritis and fibrositis.

Adopting the customary classification that rates lower than $5 \mathrm{~mm} . \mathrm{s}$ per hour indicate normality, those between 5 and $x_{5}$ are doubtful, and

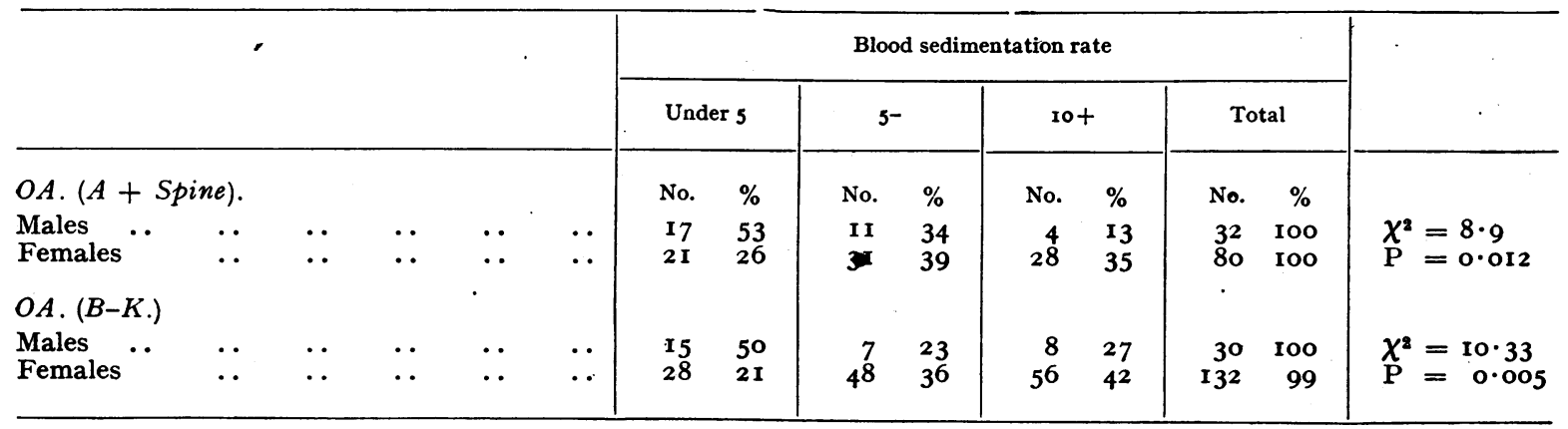

data 6r per cent of interstitial neuritis was due to sciatica, I6 per cent to brachial neuritis, and 20 per cent to Bell's palsy.

\section{Blood sedimentation rate.}

It is frequently urged that the blood sedimentation rate is a useful guide in diagnosing infective arthritis, as distinct from other types of rheumatism, since while high rates are frequently observed in infective arthritis the general opinion is that they are seldom, if ever, observed in osteoarthritis. I am aware of no published statistical evidence in support of this theory, and since the B.S.R. in $\mathrm{mm}$.s per hour was noted for each patient when treatment commenced in this series of records, it seemed an excellent opportunity to test it, restricting the examination to infective arthritis, ankylosing spondylitis, gout, fibrositis, and osteoarthritis only. In Table 22 frequency distributions are shown of the blood sedimentation rates, distinguishing those types, but excluded from the Table are those cases where it was evident that the B.S.R. was raised owing to the presence of other diseases such as pulmonary tuberculosis, psoriasis, Paget's disease, etc. The number so those of $I_{5}$ and over indicate abnormality, then for 64 per cent of infective arthritis patients the B.S.R. was abnormal, for 58 per cent. in ankylosing spondylitis, 36 per cent in gout, but only 9 per cent in fibrositis and II per cent in osteoarthritis. Combining I.A., S.A. and gout $59 \cdot 3$ per cent were high, as compared with ro per cent in the other types, a difference which is statistically significant.*

As between the sexes, real differences were found only in osteoarthritis ( $\mathrm{A}+$ Spine) and $(B-K)$, the proportion of patients with normal B.S.R. being much higher amongst males.

The conclusion to be drawn from this section seems to be that in diagnosing the type of rheumatism, after eliminating cases when a raised B.S.R. could be due to the presence of other diseases, a B.S.R. of over 50 would safely exclude osteoarthritis and fibrositis; between 20 and 50 it would strongly suggest such exclusion, but would not be an infallible guide, whilst a B.S.R. of less than 20 is no aid to diagnosis.

$$
\text { * } \chi^{2}=218.59 \mathrm{P}<0.000001 \text {. }
$$

(To be concluded) 